\title{
Maintenance therapy for recurrent epithelial ovarian cancer: current therapies and future perspectives - a review
}

\author{
Sudeep Gupta ${ }^{1 *}$, Shona Nag ${ }^{2}$, Shyam Aggarwal ${ }^{3}$, Amit Rauthan $^{4}$ and Narayanankutty Warrier ${ }^{5}$
}

\begin{abstract}
Epithelial ovarian cancer (EOC) is usually diagnosed late at an advanced stage. Though EOC initially responds to treatment, the recurrence rate is pretty high. The efficacy of different targeted therapies reduces with each recurrence. Hence there is need of effective maintenance therapy in recurrent EOC. Recently, polyADP-ribose polymerase (PARP) inhibitors (PARPi) have been approved both for initial treatment of EOC and as its maintenance treatment. PARPi have also been found to act regardless of BRCA status or homologous recombination (HR) deficiency. Several trials testing PARPi early in maintenance therapy are in progress and their results will shed light on the optimal timing of maintenance therapy that gives the most benefit with least toxicity. Right patient selection for maintenance treatment is also a challenge. Hence, though PARPi are emerging as a promising maintenance treatment in recurrent EOC with prolongation of progression free survival (PFS), results from further trials and overall survival (OS) data from current trials are awaited to fulfill the gaps in understanding the role of this pathway in treatment of EOC. This review discusses the current therapies for EOC, challenges in the treatment of recurrent EOC, recent developments and trials in recurrent EOC maintenance with special focus on PARPi and future perspectives.
\end{abstract}

Keywords: PARP inhibitors, Maintenance recurrent ovarian cancer, Epithelial ovarian cancer, Olaparib, Niraparib, Rucaparib

\section{Introduction}

Globally, ovarian cancer (OC) is the seventh most common malignancy diagnosed among women and eighth leading cause of cancer mortality [1]. In 2018, United States is burdened with approximately 22,240 new cases and 14,070 deaths related to $\mathrm{OC}$ [2]. Among Indian women, ovarian cancer is the third leading cause of cancer after breast and cervical cancer. The age-adjusted incidence rates of OC vary between 5.4 and 8.0 per 100,000 persons in different parts of the country [3].

About $85-90 \%$ of all ovarian cancers are epithelial in origin, and around $70 \%$ of all epithelial ovarian cancers (EOCs) are high-grade serous (HGS) adenocarcinoma [4]. The term EOC often includes fallopian tube carcinoma and primary peritoneal carcinoma, as they have the same

\footnotetext{
* Correspondence: sudeepgupta04@yahoo.com

${ }^{1}$ Advanced Centre for Treatment, Research \& Education in Cancer, Tata Memorial Centre, Room 305, 3rd Floor, Paymaster Shodhika, Navi Mumbai, Mumbai 410210, India

Full list of author information is available at the end of the article
}

treatment and prognosis even though they are distinct from each other $[4,5]$.

Treatment after first-line therapy in EOC is contingent to platinum-free interval (PFI) and the side-effects from the previous therapy. Platinum-based chemotherapy $(\mathrm{PBC})$ remains the mainstay of treatment in platinum sensitive disease (progression after 6 months of previous therapy). Many treatment options are being tried in recurrent EOC setting including targeted therapy with vascular endothelial growth factor (VEGF) inhibitors such as bevacizumab and tyrosine kinase inhibitors (TKI) such as pazopanib and nintedanib. While bevacizumab has shown benefit in recurrent setting, data on the efficacy of pazopanib and nintedanib in recurrent setting in platinum sensitive or platinum resistant disease (depending on whether progression occurred more than 6 months or less than 6 months after completing initial $\mathrm{PBC}$ is very limited) $[6,7]$.

Others, such as topotecan, pegylated liposomal doxorubicin (PLD), docetaxel, and etoposide have been investigated in platinum resistant disease.

(C) The Author(s). 2019 Open Access This article is distributed under the terms of the Creative Commons Attribution 4.0 International License (http://creativecommons.org/licenses/by/4.0/), which permits unrestricted use, distribution, and reproduction in any medium, provided you give appropriate credit to the original author(s) and the source, provide a link to the Creative Commons license, and indicate if changes were made. The Creative Commons Public Domain Dedication waiver (http://creativecommons.org/publicdomain/zero/1.0/) applies to the data made available in this article, unless otherwise stated. 
However, if there is no clinical benefit after two lines of therapy, there is minimal likelihood of benefit from additional lines of therapy [6].

EOC is a challenge to treat because of its notoriety at recurrence with reduced benefit $(<20 \%)$, increasing toxicities, and poor quality of life with each subsequent line of therapy. Even with the newer therapies for recurrence, there has been no increase in progression free survival (PFS) after first-line therapy although overall survival (OS) is now longer [8]. Hence, there is an unmet need to optimize treatment in recurrent EOC. With increasing consensus that goals of therapy in recurrent EOC should be palliation of cancer-related symptoms, maintenance of quality of life, and extension of life, there is a lot of interest and research focusing on maintenance treatments for recurrent EOC [9]. In this concept, EOC is treated with maintenance dose therapy while the response to previous line $\mathrm{PBC}$ is still lingering. The concept is based on the hypothesis that advanced stage EOC usually has different clonal subpopulation of malignant cells of which some eventually become resistant to firstline chemotherapy, while others may respond to continuous maintenance dose therapy [10].

Poly ADP-ribose polymerase (PARP) inhibitors (PARPi) (olaparib, rucaparib, and niraparib) have emerged as one of the best approved target therapy options for recurrent EOC, especially in case of platinum-sensitive recurrent ovarian cancer (PSROC) [11-16]. This review will therefore focus on maintenance treatment of EOC with special emphasis on platinum sensitive disease and PARPi.

\section{Challenges in treating EOC}

There is tremendous amount of research and focus on EOC as it presents in advanced stages and is the most fatal of the gynecologic malignancies. Since EOC does not have symptoms specific to cancer, there are no early screening and detection modalities [17, 18]. Thus, around $75 \%$ of women are diagnosed in advanced stage disease (FIGO IIIc or IV) [17, 18].

\section{Utility of laboratory markers in the diagnosis of EOC recurrence}

Also, there are no effective lab tests known to monitor response to therapy in EOC. Though serum tumor marker CA125 is being used for initial diagnosis and for monitoring of response to chemotherapy, there is no evidence that a raised CA125 concentration alone can predict a survival benefit. Some patients with EOC present with rising CA125 levels despite having no signs and symptoms of recurrence. Treatment is a major challenge in these patients $[19,20]$. Hence, there is need for other tumor biomarkers to assess the response to therapy.

\section{Recurrent EOC and common genetic mutations}

Hereditary mutations in the BRCA1 or BRCA2 (BRCA1/2) genes occur more frequently in patients with platinumsensitive EOC than platinum-resistant EOC [12], and these patients respond better to therapy and have greater survival benefits than women without the mutation [21]. However, routine $B R C A$ testing and $B R C A$ based treatment decisions are still at a nascent stage in India [22].

Newly diagnosed EOC is conventionally treated with de-bulking surgery and PBC in either neoadjuvant or adjuvant setting. However, even after being in full remission on first-line therapy, about $70-85 \%$ of patients with EOC relapse and median survival for patients with recurrent disease ranges from 12 months to 24 months [23]. Even with good response to treatment and survival after first recurrence on $\mathrm{PBC}$, this treatment is rarely curative [23].

\section{Importance of platinum free interval in platinum sensitive relapsed ovarian Cancer}

Upon recurrence in EOC, the choice of second-line chemotherapy is guided by the duration of response (DoR) to the prior PBC, also known as platinum-free interval (PFI), which is the time between completing initial $\mathrm{PBC}$ and progression. In patients with recurrent EOC, PFI is the most important predictor of response to subsequent lines of chemotherapy and the most important prognostic factor for PFS and OS. The longer the PFI, the higher the response rate (RR) and longer the duration of response [23].

\section{$\mathrm{PFI}$ and treatment responses in platinum sensitive relapsed EOC}

Though patients with a PFI more than 6 months have been considered as platinum-sensitive, those with a PFI more than 12 months are considered definite or highly platinum sensitive, and those falling in the group with PFI of 6 to 12 months are now considered partially platinumsensitive (PPS). However, treatment with platinum containing doublets in the PPS group gives unsatisfactory results with RR of only $25-30 \%$ to the subsequent PBC. The most effective regimen to be used in PPS is still uncertain and requires further research [7, 23-25].

It has been seen that with each recurrence the sensitivity and response to $\mathrm{PBC}$ decreases dramatically. Second-line $\mathrm{PBC}$ has a response of approximately 50-65\% [25]. In a study, $51.6 \%$ of the patients showed clinical response to second-line therapy but the response dramatically reduced to only $11.9 \%$ in third-line chemotherapy [26]. Response profiles of late lines of non-platinum-containing regimens are in the range $10-15 \%$ with a PFS benefit of about 3 to 4 months, and OS benefit of around 12 months [27]. In three large European studies comprising of 1620 patients with OC, median PFS after the first, second, third, fourth, and fifth relapse was 10.2 [95\% confidence interval (CI) 
9.6-10.7], 6.4 (5.9-7.0), 5.6 (4.8-6.2), 4.4 (3.7-4.9), and 4.1 (3.0-5.1) months, respectively. Median OS after the first, second, third, fourth, and fifth relapse was 17.6 (95\% CI 16.4-18.6), 11.3 (10.4-12.9), 8.9 (7.8-9.9), 6.2 (5.17.7), and 5.0 (3.8-10.4) months, respectively [28].

\section{Current status of selecting patients based on platinum sensitivity}

Until recent years, recurrent EOC had no treatment option other than repeated courses of chemotherapy in second-line setting and beyond, with most patients eventually becoming resistant to $\mathrm{PBC}$. Thus, selecting patients based on platinum sensitivity lost meaning after second-line therapy $[25,29,30]$. Hence, there is an unmet need for newer therapies in this area like PARPi and the concept of maintenance is gaining significance.

\section{Treatment options for platinum sensitive versus platinum resistant recurrent EOC}

Guided by PFI, either chemotherapy or targeted therapies are used for EOC recurrence.

\section{Chemotherapy}

Platinum sensitive patients are carefully selected for various combinations of PBC comprising of carboplatin or cisplatin in combination with paclitaxel, gemcitabine, PLD, or (with or without) bevacizumab [6, 7]. Combination therapy has been demonstrated to have better PFS and $O S$ advantages over single platinum-agents [7, 23, 25].

If progression after first-line therapy occurs in less than 6 months after cessation of chemotherapy, the disease is considered platinum-resistant. During treatment EOCs can become platinum refractory, which means progression occurs during chemotherapy or within 1 month of cessation of chemotherapy $[25,29,30]$. The prognosis is poor for platinum-refractory and platinum-resistant patients. A non-platinum regimen is generally considered the most appropriate approach in these patients [23, 24]. In platinum-resistant patients, single agent non-platinumcontaining therapies like PLD, paclitaxel, gemcitabine, or topotecan are recommended. Bevacizumab could be added in carefully selected patients [6].

In patients with partially sensitive recurrent EOC, the MITO-8 trial supports the use of $\mathrm{PBC}$ as platinum sensitive drugs prolong PFI and improve quality of life compared to non-platinum-based therapy [30, 31].However, when platinum is not an option due to anaphylaxis to platinum compounds, trabectedin (MITO15 phase II trial [NCT01772979]) or PLD with trabectedin (phase 3 OVA-301 study) can be considered. In these patients with anaphylaxis to platinum compound, platinum sensitive patients derived more benefit than platinum resistant patients and patients with $B R C A$ mutation had longer PFS and OS [7, 32, 33].

\section{Targeted therapies} Approved therapies

Molecularly targeted inhibitors such as VEGF inhibitors (i.e., bevacizumab) and PARPi (i.e., olaparib, rucaparib, and niraparib) have emerged as treatment options in patients with advanced EOC after multiple prior lines of chemotherapy. Careful patient selection is required for bevacizumab and PARPi therapy, however, the criteria for patient selection are still evolving [25].

Bevacizumab, in combination with paclitaxel, PLD, or topotecan is approved for the treatment of patients with platinum-resistant recurrent EOC after maximum 2 prior lines of chemotherapy [27, 34]. Bevacizumab benefit has been demonstrated in platinum resistant setting in the AURELIA study [27]. In the platinum sensitive setting, bevacizumab has been tested in the OCEANS study and GOG-213 study [35-37]. Bevacizumab along with $\mathrm{PBC}$ like carboplatin-gemcitabine or carboplatinpaclitaxel is tested in MITO16 and MANGO-2 trials and in the phase III BOOST trial (NCT01462890) [31, 38, 39]. Bevacizumab monotherapy has also shown some clinical activity in platinum resistant patients with a clinical response rate of $16-21 \%$ in 1 to 3 prior lines of chemotherapy, and $13-16 \%$ in later lines of therapy [25].

PARPi have been the most studied, most effective, and least toxic in platinum sensitive recurrent EOC both as treatment and as maintenance [11]. These have been discussed in detail in a separate section.

\section{Therapies under clinical development}

TKIs like pazopanib (a multikinase inhibitor of VEGFR13 , c-Kit and platelet-derived growth factor receptor $\alpha$ and $\beta$ ), trebananib (a fusion protein that selectively binds angiopoietin 1 and 2, preventing signaling through Tie-2 receptor), cediranib (a potent oral inhibitor of all 3VEGF receptor tyrosine kinases), nintedanib (a multi-kinase inhibitor); and immune checkpoint inhibitors like atezolizumab are being tested in various settings [7]. Success of targeted therapies lies on their specific inhibition of a driving molecule or pathway resulting in a tumor response rate of around $50-70 \%$ and a disease control rate of at least $80 \%$ [40].

Pazopanib, had demonstrated the PFS advantage in platinum-resistant and refractory OC (phase II trial: MITO-11; NCT01644825) [7, 30].

The immune checkpoint inhibitor atezolizumab in combination with PBC and bevacizumab is being tested in platinum sensitive setting in phase III randomized, double-blinded ATALANTE (NCT02891824) trial, and in AGO-OVAR 2.29 trial which is in a platinum resistant setting. Other combination trials include phase II study (EORTC-1508/NCT02659384) investigating atezolizumab with bevacizumab or acetylsalicylic acid and 
phase II/III study (NCT02839707) evaluating PLD with atezolizumab and/or bevacizumab [7].

\section{Maintenance therapy in recurrent EOC}

A comprehensive analysis of 13 randomized placebocontrolled trials studying targeted maintenance therapy in OC showed that both PFS and OS improved compared to placebo (PFS: $\mathrm{HR}=0.84,95 \%$ CI 0.75 to 0.95 , $p=0.001$; OS: $\mathrm{HR}=0.91,95 \% \mathrm{CI} 0.84$ to $0.98, p=0.02$ ). However, treatment with targeted maintenance therapy was associated with increased incidence of adverse events (AEs) such as nausea, vomiting, diarrhea, fatigue, and hypertension which required dose reductions [41].

Though several maintenance therapies for recurrent OC have been tested, but only PARPi (niraparib, rucaparib, olaparib) have been approved by the FDA and/or European Medical Association (EMA) [7]. Paclitaxel has been tested in GOG 212 trial which failed to show OS benefit and demonstrated increased toxicities after complete response to first-line therapy [42]. Bevacizumab has been investigated in GOG 218, and NCT02022917 study with inconclusive evidence of benefit in maintenance and in ICON7 with no evidence of benefit in PFS or OS in first line maintenance except in a subset of high risk patients $[43,44]$. Very few patients in high risk sub-set in ICON7 received bevacizumab in recurrent setting, and hence its use in maintenance in recurrent EOC is not known [45]. The review by Cortez et al. has shown that PARP inhibitors such as niraparib in NOVA trial, olaparib in SOLO-2; and rucaparib in ARIEL-3 trials have demonstrated positive results in their respective clinical trials [7].

Pazopanib monotherapy was evaluated in AGOOVAR16 (NCT00866697) trial and though it showed improved median PFS versus placebo 17.9 vs 12.3 months, respectively in platinum-sensitive maintenance (hazard ratio [HR], $0.77 ; 95 \%$ CI 0.64 to $0.91 ; p=0.0021$ ), further studies are required to validate these findings as OS benefit has yet not been demonstrated [30, 46].

Nintedanib has been successfully studied in a phase 3 trial in combination with chemotherapy followed by maintenance monotherapy (AGO-OVAR 12/NCT01015118). Nintedanib demonstrated significant improvement in median PFS in the treatment group compared with control group (17.2 versus 16.6 months; $\mathrm{HR}=0.84$; $95 \%$ CI $0.72-$ $0.98 ; p=0.024)$ [47]. In their review, Elit \& Hirte reported results of a phase 2 trial of nintedanib (NCT00710762) as maintenance in patients with resistant or partial PSROC which showed a higher PFS rate of $16.3 \%$ at 36 weeks compared with $5 \%$ in placebo group $(\mathrm{HR}=0.68 ; 95 \% \mathrm{CI}$ $0.44-1.07 ; p=0.07$ ) [48]. Evaluation of nintedanib in bevacizumab resistant, persistent, or recurrent EOC which does not progress for at least 6 months is in progress (NCT01669798) [7].
Preliminary data of pembrolizumab in combination with first-line PBC, followed by pembrolizumab maintenance showed promise in a small clinical trial of advanced OC presented at the 2018 Society of Gynecologic Oncology Annual Meeting [49]. Immune checkpoint inhibitors like atezolizumab are being tested in combination with bevacizumab and $\mathrm{PBC}$ in the ATALANTE (NCT02891824) trial [7].

Thus, both chemotherapy and non-PARPi targeted therapies (Table 1) either failed to give a conclusive benefit in EOC maintenance or the trials are still in progress with results awaited.

\section{Application of PARP inhibitors in the treatment of recurrent ovarian Cancer}

PARP (Fig. 1) includes a class of 17 enzymes that interrupt DNA repair, disrupt stability, and cause cell death by their action on single-strand DNA breaks or base excision repair (BER) [7].

PARPi could be useful in HGS ovarian cancers (HGSOC) as they have detectable germline and somatic mutations. Another notable characteristic seen in many HGSOC is DNA methylation of genes (e.g. BRCA1/2) which participate in homologous recombination (HR) DNA repair during epigenetic silencing. Approximately $30 \%$ of HGSOCs have BRCA1/2 mutation and silencing which frequently cause diminished HR activity. HR DNA repair is a critical step in accurate repair of DNA (Fig. 2) following double strand break (DSB) $[16,40]$. In addition, PARPi are selectively lethal in HR deficient (including $B R C A 1 / 2$-mutated) cancers as they inhibit alternate DNA repair pathways such as BER and singlestrand break repair $[16,40]$.

However, in patients with PSROC, olaparib has been shown to significantly improve PFS regardless of $B R C A$ mutation and niraparib showed improved PFS regardless of $B R C A$ mutation and homologous recombination deficiency (HRD) status $[7,16]$. This indicates that apart from HR genes, there could be other potential predicative biomarkers and mechanisms for PARPi sensitivity. It also suggests that although efficacy of both olaparib and niraparib is highest in BRCA-mutated population, other patients may benefit too as improved PFS advantage was seen in wild-type $B R C A$ positive patients with low genetic loss of heterozygosity (LOH) $[7,16]$.

The only accepted predictors of a response to PARPi are cisplatin sensitivity and presence of $B R C A 1$ or BRCA2 mutations [7].. However, the optimal timing and duration of administration of PARPi is still a matter of debate. Based on data obtained from olaparib trials, it appears that the efficacy of PARP inhibition decreases with increasing lines of chemotherapy. This suggests that use of PARPi earlier in OC treatment may be more beneficial [50]. 
Table 1 Overview of investigational non-PARP inhibitors in EOC maintenance

\begin{tabular}{|c|c|c|c|c|c|c|c|}
\hline $\begin{array}{l}\text { Trial name } \\
\text { [ClinicalTrials. } \\
\text { gov identifier] }\end{array}$ & Drug & $\begin{array}{l}\text { Mono/Combo; } \\
\text { Phase }\end{array}$ & $\begin{array}{l}\text { Patient population } \\
\text { and key eligibility }\end{array}$ & $\mathrm{N}$ & Treatment arms & $\begin{array}{l}\text { Primary } \\
\text { endpoint }\end{array}$ & Results \\
\hline GOG 212 [42] & Paclitaxel & $\begin{array}{l}\text { Mono; Phase } \\
\text { III }\end{array}$ & $\begin{array}{l}\text { Advanced EOC } \\
\text { in complete response }\end{array}$ & 1157 & Pac IV or CT-2103 (PP) & OS & $\begin{array}{l}\text { No improvement in OS; } \\
\text { increased toxicities }\end{array}$ \\
\hline ICON 7 [44] & Bevacizumab & $\begin{array}{l}\text { Combo; Phase } \\
\text { III }\end{array}$ & $\begin{array}{l}\text { Newly diagnosed } \\
\text { early or advance } \\
\text { EOC, first line }\end{array}$ & 1528 & $\begin{array}{l}\mathrm{C}+\mathrm{Pac} \text { vs } \mathrm{C}+\mathrm{Pac}+ \\
\text { bev }\end{array}$ & $\begin{array}{l}\text { PFS } \\
\text { and OS }\end{array}$ & $\begin{array}{l}\text { No improvement in PFS. } \\
\text { No improvement in OS: } \\
\text { restricted mean survival } \\
\text { time chemo vs bev group } \\
44.6 \text { months ( } 95 \% \text { Cl } 43.2-45.9) \\
\text { vs } 45.5 \text { months (Cl } 44.2-46.7) \text {; } \\
\text { log-rank ( } p=0.85 \text { ) } \\
\text { Benefit only in high-risk subset: } \\
\text { mean OS } 34.5 \text { months ( } 95 \% \mathrm{Cl} \\
32.0-37.0) \text { vs } 39.3 \text { months } \\
(37.0-41.7) \text { (log-rank } p=0.03 \text { ). }\end{array}$ \\
\hline GOG 218 [43] & Bevacizumab & $\begin{array}{l}\text { Combo; Phase } \\
\text { III }\end{array}$ & $\begin{array}{l}\text { Newly diagnosed } \\
\text { advance EOC }\end{array}$ & 1873 & $\begin{array}{l}\text { C }+ \text { Pac (TC group) } \\
\text { vs } C+P a c+\text { bev (TCP } \\
\text { group) vs } C+P a c+ \\
\text { bev followed by } \\
\text { bev maintenance }\end{array}$ & $\begin{array}{l}\text { PFS and } \\
\text { OS }\end{array}$ & $\begin{array}{l}\text { PFS improvement of } 3.8 \text { months } \\
\text { ( } 10.3 \text { for standard chemotherapy, } \\
14.1 \text { months for } \\
\text { the maintenance regimen), } \\
\text { Median OS was not significantly } \\
\text { different between arms }\end{array}$ \\
\hline $\begin{array}{l}\text { NCT02022917 } \\
{[43]}\end{array}$ & Bevacizumab & $\begin{array}{l}\text { Combo; Phase } \\
\|\end{array}$ & $\begin{array}{l}\text { Extensive stage } \\
\text { IIC or IV EOC }\end{array}$ & 27 & $\begin{array}{l}\text { Postoperative PBC } \\
\text { + adjuvant and } \\
\text { maintenance bev }\end{array}$ & AEs & $\begin{array}{l}\text { Ongoing; study completion } \\
\text { Dec } 2018\end{array}$ \\
\hline $\begin{array}{l}\text { ATALANTE } \\
\text { (NCT02891824) }\end{array}$ & Atezolizumab & $\begin{array}{l}\text { Combo; Phase } \\
\text { III }\end{array}$ & Late relapse EOC & 405 & $\begin{array}{l}\text { Atezolizumab in } \\
\text { combination with } \\
\text { PBC + bev administered } \\
\text { concurrent to } \\
\text { chemotherapy and } \\
\text { in maintenance }\end{array}$ & PFS & Ongoing; study completion 2023 \\
\hline $\begin{array}{l}\text { AGO-OVAR16 } \\
\text { (NCT00866697) } \\
{[30,46]}\end{array}$ & Pazopanib & $\begin{array}{l}\text { Mono; Phase } \\
\text { III }\end{array}$ & $\begin{array}{l}\text { Platinum-sensitive } \\
\text { maintenance in EOC }\end{array}$ & 940 & $\begin{array}{l}\text { Pazopanib } 800 \mathrm{mg} O D \\
\text { maintenance in EOC } \\
\text { patients who did not } \\
\text { progress after one line } \\
\text { of chemotherapy }\end{array}$ & PFS & $\begin{array}{l}\text { Improved median PFS vs } \\
\text { placebo } 17.9 \text { vs } 12.3 \text { months, } \\
\text { respectively (HR: } 0.77 ; 95 \% \mathrm{Cl} \text {, } \\
0.64-0.91 ; p=0.0021 \text { ) }\end{array}$ \\
\hline
\end{tabular}

PP paclitaxel poliglumex, $C$ carboplatin, $P a c$ paclitaxel, $P L D$ pegylated liposomal doxorubicin, $P B C$ platinum-based chemotherapy, $N$ patient accural, $P F S$ progression free survival, $O S$ overall survival, $H R$ hazard ratio, $C l$ confidence interval, $T C$ Chemotherapy, $T C P$ paclitaxel + carboplatin + bevacizumab, Bev bevacizumab, $A E$ adverse events, EOC epithelial ovarian cancer, $O D$ Once a day

Though PARPi have side-effects including anemia, increase in creatinine, myelodysplastic syndrome (MDS) and acute leukemia (Table 2), they are usually not as severe as those observed with chemotherapy or with other targeted therapies and are easily managed with dose reductions and modifications. About, $\leq 1 \%$ patients in both olaparib and rucaparib studies have also developed MDS/acute myeloid leukemia, highlighting the need to monitor patients for hematologic toxicities [13, 14].

In the treatment of advanced recurrent OC, PARPi continues to be tested in three distinct settings, especially after $2-3$ or more prior lines of $\operatorname{PBC}[7,11,16]$ :

1) Monotherapy (olaparib in relapsed germline $B R C A$ + ve EOC in SOLO3/ NCT02282020; rucaparib versus chemotherapy in $B R C A+$ ve EOC in ARIEL4/NCT02855944)

2) Maintenance therapy (discussed in a separate section): (ENGOT-OV16 NOVA/NCT01847274, SOLO 2/NCT01874353, ARIEL3/NCT01968213)
3) Combination therapy (niraparib versus niraparibbevacizumab ENGOTOV24/AVANOVA/ NCT02354131; olaparib or cediranib maleate and olaparib in NCI-OVM1403/NCT02446600; olaparib with paclitaxel and carboplatin versus carboplatin and paclitaxel alone in patients with PSROC in NCT01081951

\section{PARP inhibitor Monotherapy in recurrent EOC (Table 3) Approved therapies}

In late 2014, olaparib received accelerated FDA approval as monotherapy for patients with advanced OC previously treated with $\geq 3$ lines of chemotherapy and harboring deleterious or suspected deleterious germline $B R C A$ (gBRCA) mutations. Olaparib was granted accelerated approval based on an objective response rate (ORR) of $34 \%$ (46/137; 95\% CI 26-42) and median duration of response (DOR) of 7.9 (95\% CI 5.6-9.6) months in a heavily pretreated ( $\geq 3$ lines of therapy) 137 patients with advanced $\mathrm{OC}$ who had a germline $B R C A$ mutation in Study 42 [56]. This accelerated approval was contingent 


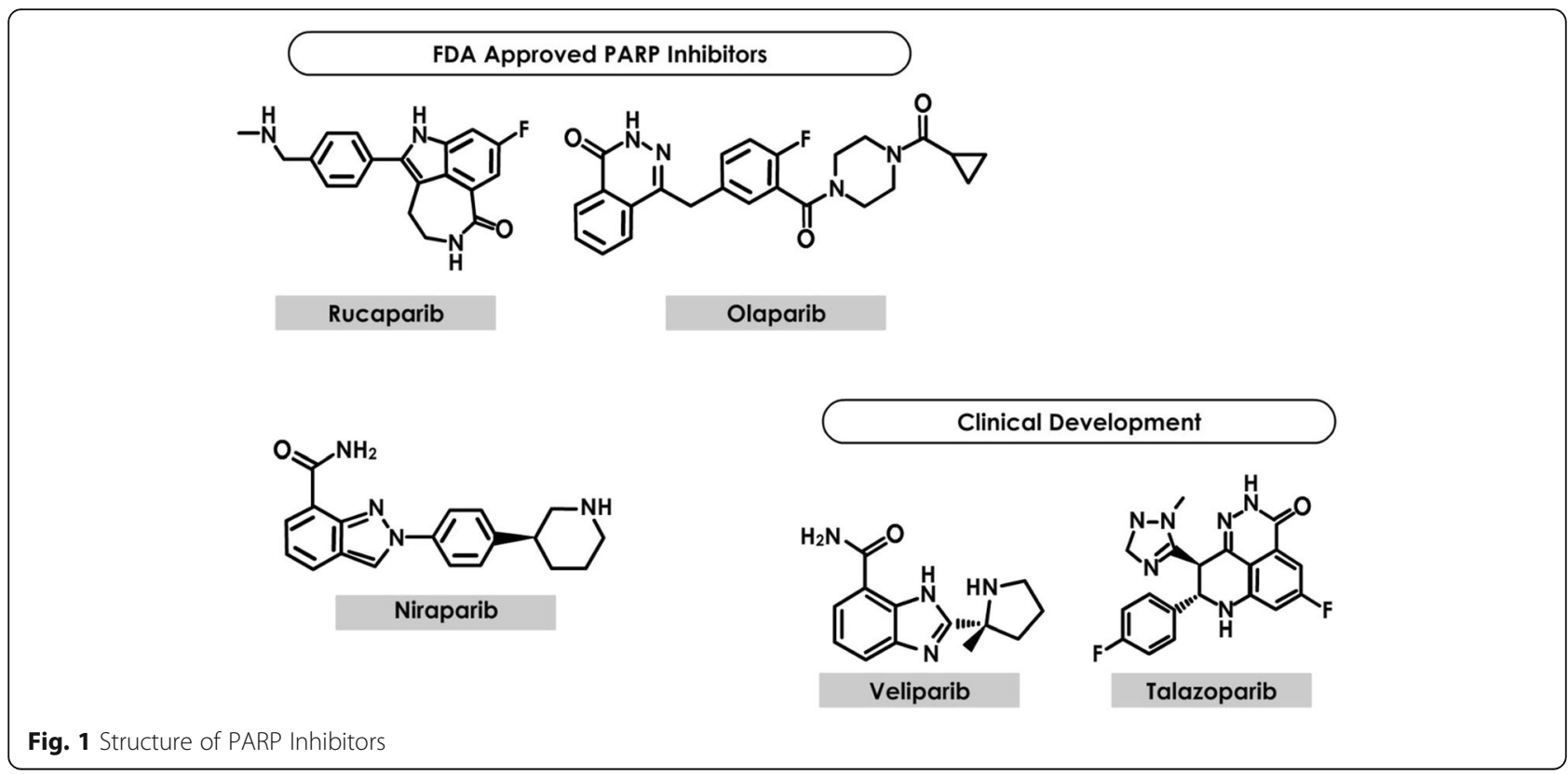

upon verification of clinical benefit from two trials: SOLO 2 which studies olaparib in PSROC with a $B R C A 1 / 2$ mutation who had received at least two lines of previous chemotherapy [51] and the phase 2 LIGHT study (NCT02983799) which assesses the efficacy and safety of olaparib in patient cohorts stratified by use of different HRD genetic tests [57].
SOLO 3 is an ongoing phase III randomized trial of olaparib vs. physicians' choice of four chemotherapy options in patients with platinum-sensitive germline BRCA mutant HGSOC, who had two or more lines of $\mathrm{PBC}[7,11]$. The results of the SOLO3 were recently presented at ASCO 2019 by Penson and colleagues showed a statistically significant and clinically meaningful

Table 2 Side effects of PARP inhibitors

\begin{tabular}{|c|c|c|c|c|c|}
\hline & & $\begin{array}{l}\text { Olaparib SOLO2/ENGOT- } \\
\text { Ov21 }(n=195)[51]\end{array}$ & $\begin{array}{l}\text { Niraparib NOVA } \\
\text { ENGOT-OV16 }(n=367) \\
{[52]}\end{array}$ & $\begin{array}{l}\text { Rucaparib ARIEL2 }(n=204) / \\
\text { ARIEL3 }(n=374)[53,54]\end{array}$ & $\begin{array}{l}\text { Veliparib }(n=50) \\
{[55]}\end{array}$ \\
\hline \multirow[t]{2}{*}{$\begin{array}{l}\text { Grade } 3 \text { and } 4 \\
\text { Adverse Events }\end{array}$} & Hematological & $\begin{array}{l}\text { Anemia } 38(18 \%) \\
\text { Neutropenia } 8(4 \%) \\
\text { Thrombocytopenia } 2(1 \%)\end{array}$ & $\begin{array}{l}\text { Anemia } 93(25.3 \%) \\
\text { Neutropenia } 72(19.6 \%) \\
\text { Thrombocytopenia } 124 \\
(33.8 \%)\end{array}$ & $\begin{array}{l}\text { Anemia } 45(22 \%) / 70(19 \%) \\
\text { Neutropenia } 16(7 \%) / 25(7 \%) \\
\text { Thrombocytopenia } 5(2 \%) / 19 \\
(5 \%)\end{array}$ & $\begin{array}{l}\text { Leukopenia } 1(2 \%) \\
\text { Neutropenia } 1(2 \%) \\
\text { Thrombocytopenia } 1 \\
(2 \%)\end{array}$ \\
\hline & $\begin{array}{l}\text { Non- } \\
\text { hematological }\end{array}$ & $\begin{array}{l}\text { Fatigue } 8(4 \%) \text { Abdominal } \\
\text { pain } 5(3 \%) \\
\text { Nausea } 5(3 \%) \text { Vomiting } 5 \\
(3 \%)\end{array}$ & $\begin{array}{l}\text { Hypertension } 30(8.2 \%) \\
\text { Fatigue } 30(8.2 \%) \\
\text { Abdominal pain } 4 \\
(1.1 \%) \\
\text { Nausea } 11(3.0 \%)\end{array}$ & $\begin{array}{l}\text { Elevated AST/ALT } 25(13 \%) / 39 \\
(10 \%) \text { Fatigue } 18(9 \%) / 25(7 \%) \\
\text { Abdominal pain } 5(2 \%) / 9(2 \%) \\
\text { Nausea } 9(4 \%) / 14(4 \%)\end{array}$ & $\begin{array}{l}\text { Nausea } 2(4 \%) \\
\text { Metabolism/nutrition } \\
1(2 \%) \\
\text { Other investigations } \\
6(12 \%)\end{array}$ \\
\hline \multirow[t]{2}{*}{$\begin{array}{l}\text { Serious Adverse } \\
\text { Events }\end{array}$} & Total & $35(18 \%)$ & Total 110 (30\%) [16] & $\begin{array}{l}\text { ARIEL2: total } 50(25 \%) \\
\text { ARIEL3: total } 78(21 \%)\end{array}$ & Total 12 (24\%) \\
\hline & Individual & $\begin{array}{l}\text { Anemia } 7(4 \%) \\
\text { Abdominal pain } 3(2 \%) \\
\text { Intestinal obstruction } 3(2 \%)\end{array}$ & & $\begin{array}{l}\text { ARIEL2: } \\
\text { Intestinal obstruction } 10(5 \%) \\
\text { Anemia } 9(4 \%) \\
\text { ARIEL3: } \\
\text { Anemia } 16(4 \%) \\
\text { Pyrexia } 6(2 \%) \\
\text { Vomiting } 6(2 \%) \\
\text { Intestinal obstruction } 3(1 \%)\end{array}$ & \\
\hline $\begin{array}{l}\text { Dose Changes due } \\
\text { to Adverse Events }\end{array}$ & & $\begin{array}{l}\text { Dose reductions } 49 \text { (25\%) } \\
\text { Discontinuations } 21(11 \%)\end{array}$ & $\begin{array}{l}\text { Dose reductions: } 244 \\
(66.5 \%) \\
\text { Discontinuations: } 54 \\
(14.7 \%)\end{array}$ & $\begin{array}{l}\text { ARIEL2: } \\
\text { Dose reductions: } 80 \text { (39\%) } \\
\text { Discontinuations: } 19 \text { (9\%) } \\
\text { ARIEL3: } \\
\text { Dose reductions: } 203(55 \%) \\
\text { Discontinuations: } 50(13 \%)\end{array}$ & $\begin{array}{l}\text { Dose Reductions: } 31 \\
(62 \%) \\
\text { Discontinuations: } 31 \\
(62 \%)^{a}\end{array}$ \\
\hline
\end{tabular}




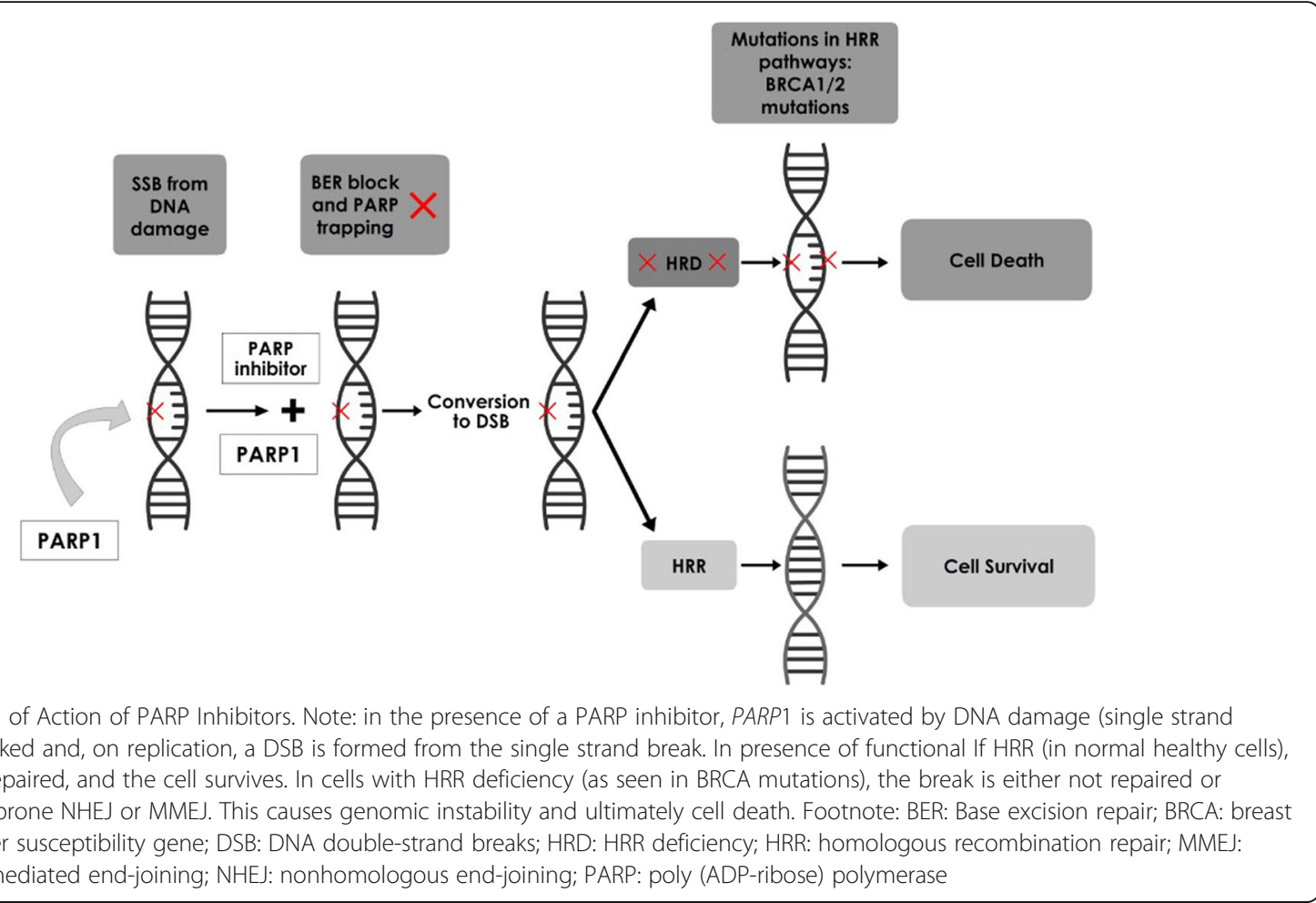

ORR and PFS benefit with olaparib versus non - platinum based chemotherapy.

In late 2016, rucaparib, another PARP inhibitor was approved as monotherapy for patients with PSROC that progressed with $\geq 2$ lines of chemotherapy and harboring deleterious BRCA mutation (germline or somatic). The accelerated approval was based upon positive results from ARIEL2 Part 1 study, which demonstrated significantly longer PFS in the $B R C A$ mutant (hazard ratio [HR] 0.27, 95\% CI 0.16-0.44, $p<0.0001)$ and LOH high $(0.62,0.42-$ $0.90, p=0.011)$ subgroups compared with the LOH low subgroup. Part 2 of the ARIEL2 trial is ongoing (NCT01891344) [14, 53, 54]. Ongoing studies (Study 10 Part 2B, ARIEL2 Part2, ARIEL4) are evaluating rucaparib treatment in both platinum sensitive and resistant patient population [59].

\section{PARP inhibitors combination therapy in recurrent EOC (Table 3)}

Various olaparib or veliparib combinations with chemotherapy have been tried as it was thought that BER disruption via $P A R P$ inhibition would synergize with chemotherapy $[58,60]$. However, when PARPi are combined with chemotherapy, full doses of both regimens are rarely achieved as they both have overlapping myelosuppressive toxicities [61].

Hence PARPi combinations with biologics like antiangiogenics or PI3 kinase pathway inhibitors or immune checkpoint inhibitors and other biologic agents are under way, especially for HSGOC, in the hope of inducing greater DNA damage and HRD with lesser toxicities than chemotherapy combinations [11]. Phase I studies of olaparib in combination with the PI3K inhibitor BKM120 (NCT01623349) and the AKT inhibitor AZD5363 (NCT02208375) have demonstrated evidence of activity in OC [62, 63].

Olaparib alone or in combination with cediranib was tested in a phase 2 study in platinum-sensitive recurrent HGSOC (both germline and sporadic BRCA positive) (NCT01116648). Median PFS was 17.7 months for cediranib and olaparib group $(n=44)$ versus 9.0 months for olaparib group $(n=46 ; \mathrm{HR}=0.42 ; p=0.005)$. Though OS data were not mature at the time of reporting, the combination group demonstrated a trend toward longer OS [7, 11, 64]. Based on these positive results, two phase III trials are underway in both platinum sensitive and platinum resistant OC. Olaparib or cediranib alone or in combination compared with standard chemotherapy is being tested in platinum-resistant EOC in a randomized phase II/III trial, NRG-GY005 (NCT02502266). Olaparib versus olaparib/ cediranib versus platinum doublet in BRCA stratified platinum sensitive recurrent HGSOC is being tested in NRGGY004 (NCT02446600) trial. The phase III PAOLA - 1 trial (see Table 4) (NCT02477644) is evaluating a combination of Olaparib and Bevacizumab maintenance post platinum-based chemotherapy in 1st line Ovarian cancer irrespective of BRCA status $[11,66]$. 


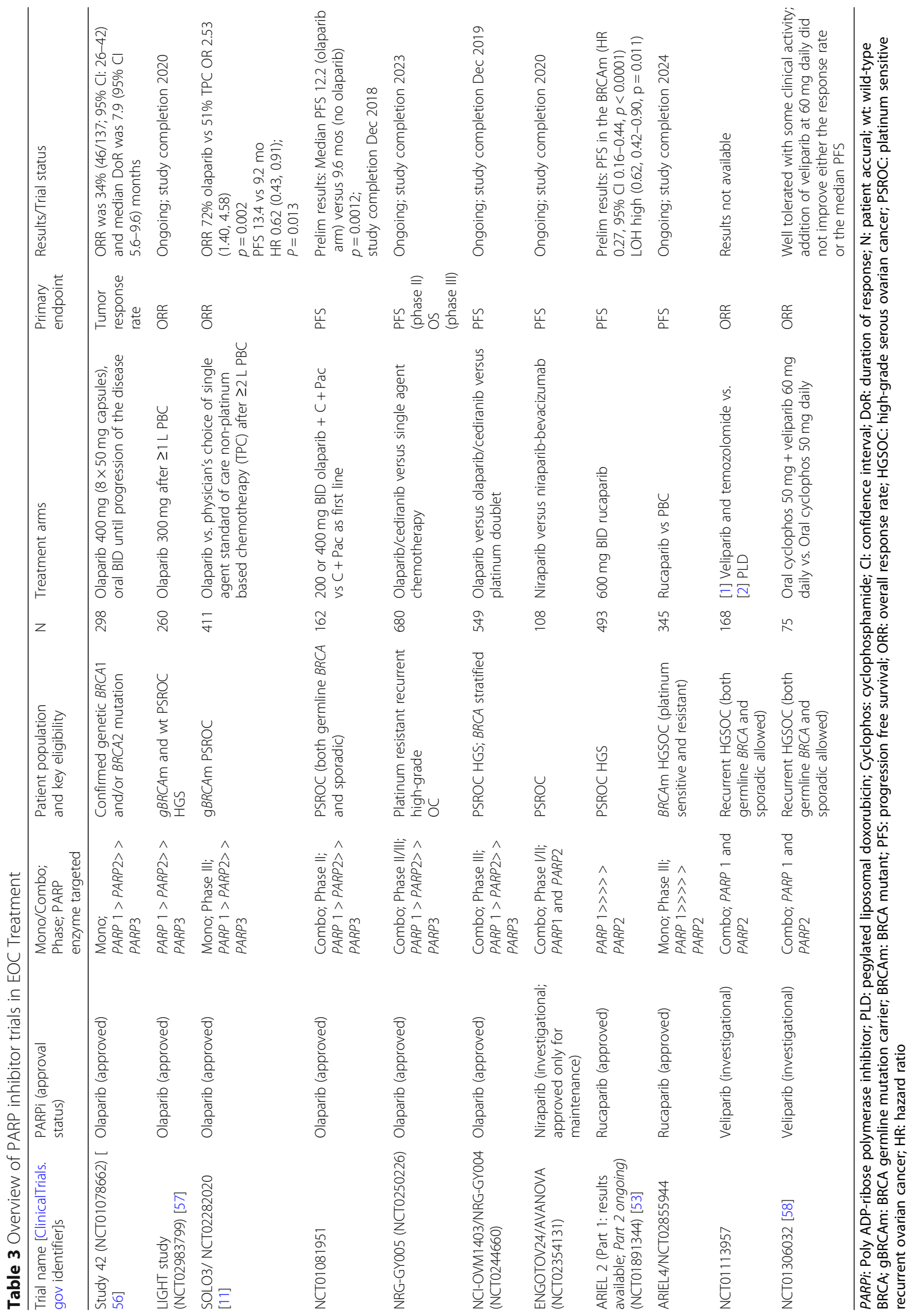




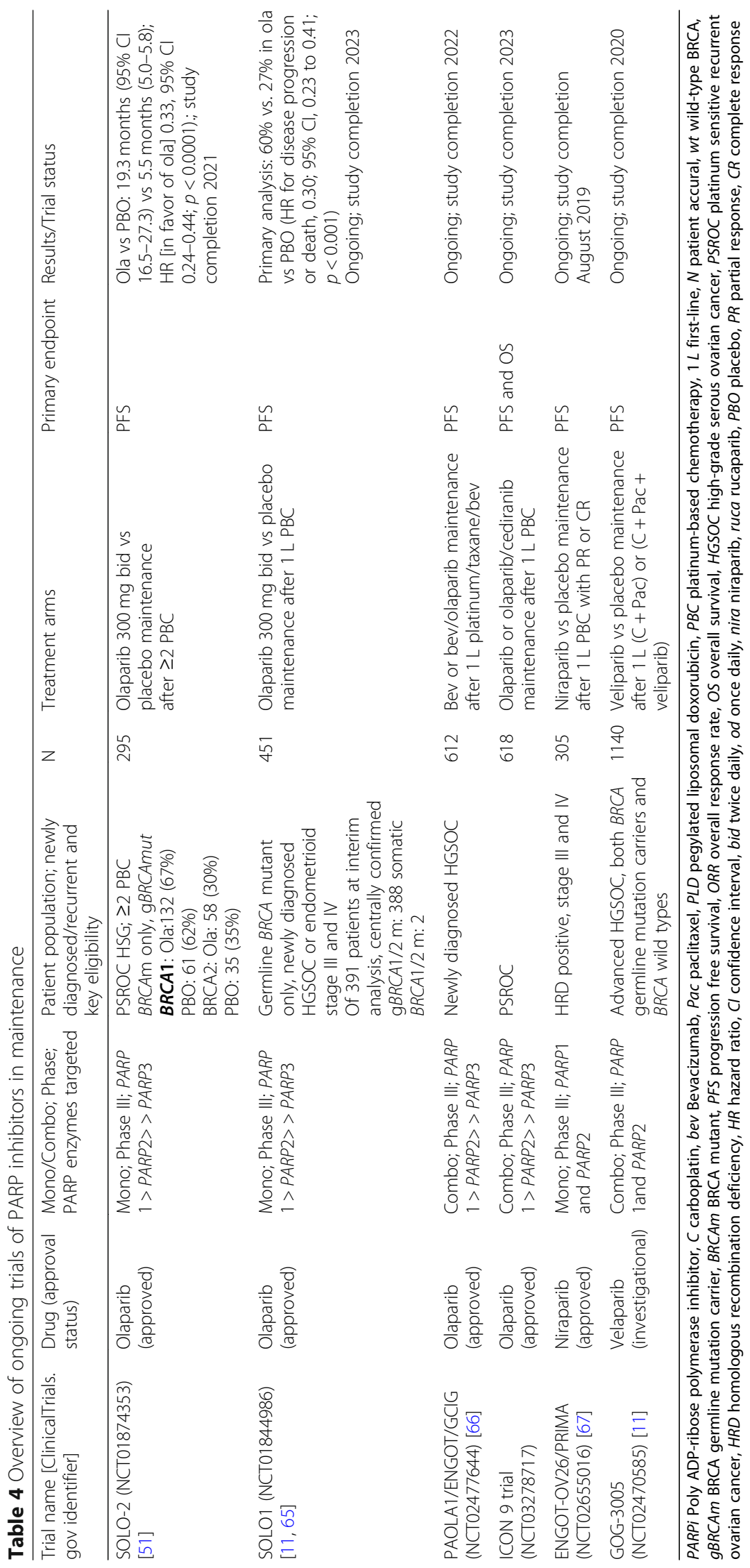




\section{Third-line and beyond in EOC - the unmet need} Patients with EOC having 3 or more recurrences have few effective treatment choices. Thus, several clinical trials are investigating treatment options in EOC for these patients. Various single and combination agents are being tried in late stage trials namely PARPi (ricaparib, niraparib, and olaparib), NUC-103 (gemcitabine prodrug), mirvetuximab soravtansine (an antibody-drug conjugate targeting the folate-alpha receptor), trabectedin (novel alkylating chemotherapy agent), birinapant (SMAC mimetic and IAP inhibitor), and volasertib (Plk1 inhibitor) [25].

Ovarian cancer with $B R C A 1 / 2$ mutations can also recur after $\geq 3$ lines of therapy. $B R C A 1 / 2$ mutant EOC has shown susceptibility to PARP inhibitors due to synthetic lethality (Table 5). In a phase 2 study (Study 42, NCT01078662), olaparib has shown positive results in germline $B R C A 1 / 2$ mutant positive OC patients with $\geq 3$ recurrences and stratified by platinum sensitivity [56].

Table 5 PARPi Maintenance by HRD Status

\begin{tabular}{|c|c|c|c|c|}
\hline Study & Phase & Patient population & Treatment arms & HR classification \\
\hline $\begin{array}{l}\text { Study } 19 \\
{[12,68]}\end{array}$ & $\|$ & $\begin{array}{l}\text { Platinum-sensitive recurrent } \\
\text { serous ovarian cancer; } \geq 2 \\
\text { PBC with PR or CR to most } \\
\text { recent PBC }\end{array}$ & $\begin{array}{l}\text { olaparib } 400 \mathrm{mg} \\
\text { bid vs PBO }\end{array}$ & $\begin{array}{l}\text { Germline or tumor BRCA } \\
\text { Ola: } 74(56 \%) \text { vs PBO } \\
62(50 \%)\end{array}$ \\
\hline
\end{tabular}

PFS/OS/ORR

PFS: ola: 11.2 months (BRCAm)/7.4 months (wt) $p<0.00001$, For PBO: 4.3 months $(B R C A m) / 5.5$ months (wt); $p=0.007$

OS: BRCAm ola vs PBO 34.9 months (95\% Cl 29.2-54.6) vs 30.2 months (23.1-40.7); HR 0.62 (95\% Cl 0.410.94) nominal $p=0.025 B R C$ Awt in11 (15\%) of 74 patients with $B R C A m$ who received ola maintenance for $\geq 5$ years: ola vs PBO: 24.5 months (19.8-35.0) vs 26.6 months (23.1-32.5); HR 0.83 (95\% Cl 0.55-1.24); nominal $p=0.37$

$\begin{array}{lll}\begin{array}{ll}\text { SOLO1 } \\ \text { (NCT01844986) }\end{array} & \text { III } & \begin{array}{l}\text { Newly diagnosed HGSOC } \\ \text { Or endometrioid stage III } \\ \text { and IV }\end{array} \\ {[11,65]} & \quad \text { III } & \text { PSROC HSG; } \geq 2 \text { PBC }\end{array}$

olaparib $300 \mathrm{mg}$ Of 391 patients at interim bid vs PBO

bid vS PBO
analysis, centrally confirmed gBRCA1/2 m: 388 somatic BRCA1/2 m: 2

olaparib 300 mg bid vs PBO gBRCAmut BRCA1: Ola:132 (67\%); PBO: 61 (62\%) BRCA2: Ola: 58 (30\%); PBO: 35 (35\%)

Niraparib 300 mg vs. PBO o.d

ENGOT-OV16/NOVA [52] ॥ PSROC
$B R C A 1 / 2$ positive \& $B R C A 1 / 2$ negative gBRCA cohort: 203 (niraparib: 138,PBO: 65) non-gBRCA cohort: 350 (niraparib: 234, PBO: 116

\section{Rucaparib maintenance therapy $600 \mathrm{mg}$ p.o. b.i.d. vs. $\mathrm{PBO}$ \\ HRD stratification at the time of enrollment (BRCAmut; BRCAwt/ LOH \\ Median PFS in BRCA-mut rucaparib vs PBO $16.6 \mathrm{mo}$ (95\% Cl 13.4-22.9) vs. 5.4 mo (95\% Cl 3.4-6.7) (HR 0.23 [95\% Cl 0.16-0.34]; $p<0.0001$ ) HRD carcinoma ruca vs PBO: $13.6 \mathrm{mo}(10.9-16.2)$ vs 5.4 mo (5.1-5.6; 0.32 [0.24-0.42]; $p<0.0001)$} or CR to most recent $\mathrm{PBC}$

$\begin{array}{lll}\text { ARIEL3 (NCT01968213) } & \text { III } & \text { PSROC- HSGOC, } \geq 2 \\ {[54,69]} & & \text { prior PBC with PR } \\ \text { Ongoing; completion } & \text { or CR to most } \\ \text { June 2020 } & \text { recent PBC }\end{array}$

PFS: Primary analysis: 60\% vs. $27 \%$ in ola vs PBO (HR for disease progression or death, $0.30 ; 95 \% \mathrm{Cl}, 0.23$ to 0.41 ; $\mathrm{p}<0.001$ )

In 286 patients with $B R C A 1 / 2$ (Ola: 190; PBO: 96). median PFS Ola vs PBO (19.3 months [95\% Cl 16.5-27.3] vs 5.5 months [5.0-5.8]; HR [in favor of ola] $0.33,95 \% \mathrm{Cl} 0.24-0.44$; $p<0.0001)$.

Median PFS gBRCAm $21 \mathrm{mo}$ (nira) vs 5.5 months (PBO) (HR, 0.27; 95\% confidence interval [Cl], 0.17 to 0.41 ), $p<0.00001$; Non-gBRCAm HRD+ 12.9 months (nira) versus 3.8 months (PBO) (HR 0.38 95\% Cl, 0.24 to 0.59), $p<0.00001$; All Non-gBRCAm 9.3 months (nira) versus 3.9 months (PBO) (HR .45; 95\% $\mathrm{Cl}, 0.34$ to 0.61$), \mathrm{p}<0.00001$

Abbreviations: $A E$ adverse event, bid. twice daily, od once daily, p.o. orally or per mouth, chemo chemotherapy, $H R D$ homologous recombination deficiency, $H R$ hazard ratio, IV intravenous, $L O H$ loss of heterozygosity, mut mutated, N/A not available, mo months, ORR overall response rate, PARP Poly (ADP-ribose) polymerase, PFS progression-free survival, po. by mouth, wt wild type, gBRCA germline BRCA mutation, non-gBRCA non-germline BRCA mutation, $P S R O C$ platinum sensitive recurrent ovarian cancer, $H R$ hazard ratio, $P B C$ platinum based chemotherapy, Ola olaparib;nira: niraparib; ruca: rucaparib, $P B O$ placebo, $P R$ partial response, $C R$ complete response 
Olaparib demonstrated ORR of 46,30 and $14 \%$ in patients considered platinum sensitive (but not considered suitable to receive further $\mathrm{PBC}$ ), platinum resistant, and platinum refractory, respectively. ORRs with olaparib were in the range of $50-57 \%$ and $31-39 \%$ for platinumsensitive and platinum-resistant patients, respectively. Patients who received $\geq 6$ prior lines of therapy had much lower ORR of 20 and 13\% for platinum-sensitive and platinum-resistant patients, respectively. Median PFS was 9.4 months (95\% CI 6.7-11.4) and 5.5 months (95\% CI 4.2-6.7) in platinum-sensitive and platinumresistant patients, respectively [56].

The results of these trials may open new treatment opportunities for EOC with unmet needs. Also, the concept of maintenance therapy is likely to prolong time to recurrence by treating with therapies approved in this setting during the window when the response to previous line chemotherapy is still lingering.

To provide benefit in this setting, US FDA has accepted the concept of maintenance therapy and has been granting accelerated approvals to drugs for both recurrent EOC and for maintenance therapy setting [25].

\section{Role of PARP inhibitors in maintenance therapy Approved therapies (Table 5)}

All 3 PARP inhibitors - olaparib, niraparib and rucaparib have been approved as maintenance monotherapies in patients with PSROC $[13,15,51]$.

\section{Olaparib}

Of all the PARPi, olaparib has been the most extensively tested molecule in the clinical setting with favorable results [51]. Olaparib is a potent PARPi that is selectively cytotoxic to cells, blocks PARP from repairing damaged single-strand DNA breaks and preserves repair of efficient cells expressing deleterious BRCA1/2 [70].

The accelerated olaparib approvals came based on positive results from phase 3 SOLO2 and phase 2 Study 19 $[12,51]$. SOLO2 investigated olaparib maintenance after $\geq 2$ lines of chemotherapy for OC patients with germline $B R C A$ mutations. The study demonstrated that olaparib significantly improved PFS (Investigator assessed) compared to placebo (19.1 months vs. 5.5 months; $H R=0.30$ [95\% CI 0.22-0.41], $p<0.0001$ ) with marked improvement in quality of life. The most common AEs of grade 3 or worse severity were anemia (19\% in olaparib group vs $2 \%$ in the placebo group), neutropenia ( $5 \%$ vs $4 \%$ ) and fatigue or asthenia ( $4 \%$ vs $2 \%$ ). Serious adverse events were experienced by 18 and $8 \%$ of patients in the olaparib and placebo group, respectively [51]. OS results have not yet been reported [51, 71]. In the phase 2 Study 19 (AZ19/ NCT00753545), in patients with OC irrespective of BRCA status, olaparib increased PFS compared with placebo (median PFS 8.4 months versus 4.8 months; $\mathrm{HR}=0.35$; 95\% CI 0.25-0.49; $p<0.0001$ ) [12].

The phase III SOLO-1 trial evaluated the efficacy of olaparib as maintenance therapy in patients with newly diagnosed advanced HGSOC with BRCA1, BRCA2, or both $(B R C A 1 / 2)$ mutations who had a complete or partial clinical response after $\mathrm{PBC}$. The recently published results of SOLO-1) demonstrated that the olaparib group had $70 \%$ lower risk of disease progression or death than with placebo group after a median follow-up of 41 months. The Kaplan-Meier estimate of the rate of freedom from disease progression and from death at 3 years was $60 \%$ in olaparib and 27\% in the placebo group (PFS NR vs 13.8 months in placebo arm; HR for disease progression or death, 0.30 ; $95 \%$ CI, 0.23 to $0.41 ; p<0.001$ ) [65]. The olaparib arm had an unprecedented estimated 36 month benefit over placebo arm in PFS. The median time to the first subsequent therapy or death was 51.8 months vs 15.1 months in the olaparib vs placebo group, respectively (HR, 0.30 ; $95 \%$ CI, 0.22 to 0.40 ) and this benefit seemed to be maintained in the PFS2 as well, in spite of the fact that $35 \%$ of the patients in the placebo arm received a post progression PARP inhibitor (31\% maturity, HR, 0.50; 95\% CI, 0.35 to $0.72 ; \mathrm{p}<0.001$ ) [65].

Since 2016, the NCCN [3] has included olaparib in its guidelines as a fourth-line treatment for women with EOC who carry a deleterious $B R C A 1 / 2$ gene (both germline and somatic). In February 2018, the approval for use as maintenance treatment came regardless of patients' $B R C A$ mutation status thus increasing its reach to a wider set of population $[6,72]$.

In 344 patients with newly diagnosed germline BRCA mutant HGSOC or endometrioid stage III and IV, olaparib versus placebo maintenance is being tested early post PBC in SOLO1 (NCT01844986) trial [11].

\section{Niraparib}

The accelerated niraparib approvals came based on positive results from the phase 3 NOVA study which compared response in germline $B R C A(g B R C A)$ mutation positive and negative patients. While patients on both groups showed significant benefit, those in the gBRCA cohort, showed significantly longer PFS than placebo [52]. OS results have not yet been reported [50]. Approximately two thirds of patients did not have germline $B R C A$ mutations. PFS (by BICR) in the germline $B R C A$ mutations versus placebo was 21.0 months vs 5.5 months $(p<0.0001)$. In the group with non-mutated $B R C A$ but with HRD positive score versus placebo, PFS was 12.9 months vs 3.8 months $(\mathrm{p}<0.0001)$. PFS was longer in niraparib-treated patients (6.0 versus 3.9 months, $p=$ 0.02 ) even in the group without mutations and HRD negative. In patients with germline $B R C A$ mutations versus those without mutations, niraparib reduced the risk 
of progression or death by $74 \%(\mathrm{HR}=0.26)$ vs $55 \%$ $(\mathrm{HR}=0.45)$. Majority of AEs were hematological and could be successfully managed by dose modification. Thus, niraparib use is independent of $B R C A$ status and HRD score [50, 52].

Additionally, early use of niraparib versus placebo as maintenance post-response to first-line $\mathrm{PBC}$ is being tested in 305 patients with HRD positive, stage III and IV newly diagnosed OC in the ENGOT-OV26/PRIMA (NCT02655016) trial [67].

\section{Rucaparib}

On April 6, 2018 FDA approved rucaparib as maintenance therapy for recurrent EOC [14]. Approval was based on the ARIEL3 study with similar enrollment criteria as olaparib and niraparib maintenance therapy studies. However, the enrollment was not dependent on BRCA status. In the phase III ARIEL3 [NCT01968213] trial, the median PFS of maintenance rucaparib versus placebo group was 10.8 months vs 5.4 months. The median PFS was higher in patients with germline or somatic BRCA mutations: 16.6 months (95\% CI 13.4-22.9) vs 5.4 months (95\% CI 3.4-6.7) in maintenance rucaparib versus placebo group, respectively. The PFS was 13.6 months $(\mathrm{HR}=0.32, p<0.0001)$ in the HRD-group (including $B R C A$ mutant or $B R C A$ wild type/LOH-high) and 10.8 months $(\mathrm{HR}=0.37, \mathrm{p}<0.0001)$ in the "intent to treat" group (including $B R C A$ mutant, $B R C A$ wild type and LOH-low, indeterminate or high) [73] These patients also experienced a $77 \%$ reduction in the risk of progression or death with rucaparib versus placebo (HR, 0.23; 95\% CI 0.16-0.34; $p<.0001)$. To determine the HRD status, the FDA concurrently approved the complementary diagnostic test, FoundationFocus ${ }^{\mathrm{Tn}} \mathrm{CDx} B R C A \mathrm{LOH}[54,59]$.

Foote et al. (2018) assessed the relative value of maintenance therapies and biomarkers in PSROC and presented the results at the 49th Society of Gynecologic Oncology (SGO) Annual Meeting on Women's Cancers in March 2018. The value of each drug and biomarker in maintenance setting of EOC was validated using the American Society of Clinical Oncology (ASCO)'s Net Health Benefit (NHB) and the European Society of Medical Oncology (ESMO)'s Magnitude of Clinical Benefit Scale (MCBS). The following drugs and trials were examined: Study 19, NOVA, SOLO2, and ARIEL3 trials for PARPi, OCEANS, and GOG 213 trials for bevacizumab treatments, ICON6 for cediranib [74].

In germline/somatic-BRCA mutation cohorts being treated with maintenance PARPi had the highest ASCO scores: olaparib $(\mathrm{SOLO} 2)=47$, $($ Study 19$)=62$; niraparib $(\mathrm{NOVA})=50$; rucaparib $($ ARIEL3 $)=54$. ESMO scores were also high for maintenance PARPi in germline/somaticBRCA mutation cohorts. Low value scores were seen for bevacizumab, cediranib, and wild-type BRCA [74].
Based on their efficacy and safety profile and ease of oral administration PARPi are emerging as a potential maintenance therapy in recurrent $\mathrm{EOC}$ with response to $\leq 2$ prior lines of $\mathrm{PBC}$ [11].

However, despite their advantage as a safe and efficacious maintenance treatment in EOC, PARPi are costlier than the other available therapies. PARPi are 18.8, 6.9, and 2.2-2.7 times costlier than paclitaxel, pembrolizumab, and bevacizumab, respectively. Hence, it is important to carefully select the patients and optimize the timing of PARPi maintenance in order to give the most adequate response [75].

PARP inhibitor therapies in clinical development (Table 3) Veliparib, an oral PARP1 and PARP2 inhibitor has demonstrated a response rate of $26 \%$, with a median PFS of 18.8 months in phase 2 study as monotherapy in relapsed germline $B R C A$ mutant $\mathrm{OC}$, but results need to be validated in larger phase 3 trials [55].

Talazoparib, another oral PARP1 and PARP2 inhibitor was studied in phase I trials and showed some clinical activity in relapsed gBRCA mutant OC. However, currently it is not being actively pursued [11].

\section{PARP inhibitors for maintenance therapies in clinical development (Table 4)}

In women with PSROC, maintenance olaparib in combination with cediranib is currently being tested in ICON 9 trial (NCT03278717). Various combination trials testing early use of maintenance therapy in newly diagnosed OC in response to first-line therapy are underway. The GOG3005 (NCT02470585) trial is testing veliparib versus placebo maintenance therapy following carboplatin and paclitaxel or carboplatin, paclitaxel, and veliparib in 1100 patients with advanced HGSOC, both BRCA germline mutation carriers and BRCA wild types.

\section{Summary}

There is adequate data to support maintenance treatment in recurrent EOC, and the use of PARPi in the treatment (olaparib and rucaparib) and maintenance (olaparib, rucaparib, and niraparib) setting for platinumsensitive HGSOC regardless of BRCA status or HR deficiency in relapsed platinum sensitive ovarian cancer. The recently reported results of SOLO -1 marks the foray of olaparib as an effective maintenance therapy in newly diagnosed gBRCA positive ovarian cancer patients who are in CR or PR to 1st line surgery and platinumbased chemotherapy. The AEs with all the PARPi can be majorly managed with dose interruptions or modifications. Olaparib is the most studied safe and efficacious treatment and maintenance therapy in the platinum sensitive setting. Though many combination therapies with PARPi are under trial, there is no trial-based comparison 
among these three approved PARPi. Hence the relative efficacy or toxicity of the individual drugs is not known. Several trials testing PARPi early in maintenance therapy are in progress and their results will shed light on the optimal timing of maintenance therapy that gives the most benefit with least toxicity. Right patient selection for maintenance treatment is also a challenge. Hence, though PARPis are emerging as a promising maintenance treatment in recurrent EOC with prolongation of PFS, results from further trials are awaited to fulfill the gaps in understanding the role of this pathway in treatment of EOC.

\section{Acknowledgements}

The authors thank AstraZeneca Pharma India Ltd., Bangalore for providing medical writing assistance in the development of this manuscript, in collaboration with Turacoz Healthcare Solutions, Gurugram, India.

\section{Authors' contributions}

All named authors meet the International Committee of Medical Journal Editors (ICMJE) criteria for authorship for this article, take responsibility for the integrity of the work as a whole, and have given their approval for this version to be published.

\section{Funding}

The preparation of this article and funding of the journal's article processing charges was supported by AstraZeneca Pharma India Limited.

\section{Availability of data and materials}

Not applicable.

\section{Ethics approval and consent to participate}

Not applicable.

\section{Consent for publication}

Not applicable.

\section{Competing interests}

Sudeep Gupta declares institutional financial interests for conducted research from: Roche, Sanofi, Johnson \& Johnson, Amgen, Celltrion, Oncosten, Novartis, Intas, Eisai, Biocon, Astrazeneca and non-remunerated activities (Advisory Board) from: Roche, Sanofi, Dr. Reddy's Laboratories, Biocon, Pfizer, Oncosten, Core Diagnostics, Astrazeneca. Shona Nag, Shyam Aggarwal, Amit Rauthan and Narayankutty Warrier declare that they have no conflict of interest.

\section{Author details}

${ }^{1}$ Advanced Centre for Treatment, Research \& Education in Cancer, Tata Memorial Centre, Room 305, 3rd Floor, Paymaster Shodhika, Navi Mumbai, Mumbai 410210, India. ${ }^{2}$ Jehangir Hospital, Pune, India. ${ }^{3}$ Sir Gangaram Hospital, New Delhi, India. ${ }^{4}$ Manipal Hospital, Bangalore, India. ${ }^{5}$ MVR Cancer Centre and Research Institute, Calicut, India.

Received: 2 May 2019 Accepted: 10 October 2019

Published online: 04 November 2019

\section{References}

1. Coburn SB, Bray F, Sherman ME, Trabert B. International patterns and trends in ovarian cancer incidence, overall and by histologic subtype. Int J Cancer. 2017;140(11):2451-60.

2. SEER. Cancer Stat Facts: Ovarian Cancer, https://seer.cancer.gov/statfacts/ html/ovary.html. 2018; https://seer.cancer.gov/statfacts/html/ovary.html.

3. National Cancer Registry Programme ICoMR. Three-Year Report of Population Based Cancer Registries 2012-2014; Incidence, distribution, trends in incidence rates and Projections of Burden of Cancer 2012-2014.

4. Devouassoux-Shisheboran M, Genestie C. Pathobiology of ovarian carcinomas. Chin J Cancer. 2015;34(1):50-5.
5. Erickson BK, Conner MG, Landen CN Jr. The role of the fallopian tube in the origin of ovarian cancer. Am J Obstet Gynecol. 2013;209(5):409-14.

6. Ovarian Cancer, Including Fallopian Tube Cancer and Primary Peritoneal Cancer, Version 2.2018. 2018. https://www.nccn.org/professionals/physician_ gls/pdf/ovarian.pdf.

7. Cortez AJ, Tudrej P, Kujawa KA, Lisowska KM. Advances in ovarian cancer therapy. Cancer Chemother Pharmacol. 2018;81(1):17-38.

8. Kyrgiou M, Salanti G, Pavlidis N, Paraskevaidis E, loannidis JP. Survival benefits with diverse chemotherapy regimens for ovarian cancer: meta-analysis of multiple treatments. J Natl Cancer Inst. 2006;98(22): 1655-63.

9. Corrado G, Salutari V, Palluzzi E, Distefano MG, Scambia G, Ferrandina G. Optimizing treatment in recurrent epithelial ovarian cancer. Expert Rev Anticancer Ther. 2017;17(12):1147-58.

10. Tayama S, Motohara T, Narantuya D, et al. The impact of EpCAM expression on response to chemotherapy and clinical outcomes in patients with epithelial ovarian cancer. Oncotarget. 2017;8(27):44312-25.

11. Evans T, Matulonis U. PARP inhibitors in ovarian cancer: evidence, experience and clinical potential. Ther Adv Med Oncol. 2017;9(4):253-67.

12. Ledermann J, Harter P, Gourley $C$, et al. Olaparib maintenance therapy in patients with platinum-sensitive relapsed serous ovarian cancer: a preplanned retrospective analysis of outcomes by BRCA status in a randomised phase 2 trial. Lancet Oncol. 2014;15(8):852-61.

13. Olaparib Prescribing Information by FDA. LYNPARZA ${ }^{\circledast}$ (olaparib) tablets, for oral use. 2014; https://www.accessdata.fda.gov/drugsatfda_docs/label/201 8/208558s001lbl.pdf.

14. Rucaparib Prescribing Information F. RUBRACA ${ }^{\text {TM }}$ (rucaparib) tablets, for oral use 2016.

15. Niraparib Prescribing Information F. ZEJULATM (niraparib) capsules, for oral use. 2017.

16. Bitler BG, Watson ZL, Wheeler $\amalg$, Behbakht K. PARP inhibitors: clinical utility and possibilities of overcoming resistance. Gynecol Oncol. 2017;147(3):695-704

17. Lokadasan R, James FV, Narayanan G, Prabhakaran PK. Targeted agents in epithelial ovarian cancer: review on emerging therapies and future developments. Ecancermedicalscience. 2016;10:626.

18. Kim A, Ueda Y, Naka T, Enomoto T. Therapeutic strategies in epithelial ovarian cancer. J Exp Clin Cancer Res. 2012;31:14.

19. Abu Hassan SO, Nielsen DL, Tuxen MK, Petersen PH, Soletormos G. Performance of seven criteria to assess CA125 increments among ovarian cancer patients monitored during first-line chemotherapy and the posttherapy follow-up period. Future Sci OA. 2017;3(3):FSO216.

20. Rustin GJ, van der Burg ME, Griffin CL, et al. Early versus delayed treatment of relapsed ovarian cancer (MRC OV05/EORTC 55955): a randomised trial. Lancet. 2010;376(9747):1155-63.

21. Neff RT, Senter L, Salani R. BRCA mutation in ovarian cancer: testing, implications and treatment considerations. Ther Adv Med Oncol. 2017;9(8):519-31.

22. Singh J, Thota N, Singh S, et al. Screening of over 1000 Indian patients with breast and/or ovarian cancer with a multi-gene panel: prevalence of BRCA1/ 2 and non-BRCA mutations. Breast Cancer Res Treat. 2018;170(1):189-96.

23. Chuang YT, Chang CL. Extending platinum-free interval in partially platinum-sensitive recurrent ovarian cancer by a non-platinum regimen: its possible clinical significance. Taiwan J Obstet Gynecol. 2012;51(3):336-41.

24. Tomao F, D'Incalci M, Biagioli E, Peccatori FA, Colombo N. Restoring platinum sensitivity in recurrent ovarian cancer by extending the platinumfree interval: myth or reality? Cancer. 2017;123(18):3450-9.

25. Herzog TJ, Monk BJ. Bringing new medicines to women with epithelial ovarian cancer: what is the unmet medical need? Gynecol Oncol Res Pract. 2017;4:13.

26. Bruchim I, Jarchowsky-Dolberg O, Fishman A. Advanced (>second) line chemotherapy in the treatment of patients with recurrent epithelial ovarian cancer. Eur J Obstet Gynecol Reprod Biol. 2013;166(1):94-8.

27. Pujade-Lauraine E, Hilpert F, Weber B, et al. Bevacizumab combined with chemotherapy for platinum-resistant recurrent ovarian cancer: the AURELIA open-label randomized phase III trial. J Clin Oncol. 2014;32(13):1302-8.

28. Hanker LC, Loibl S, Burchardi N, et al. The impact of second to sixth line therapy on survival of relapsed ovarian cancer after primary taxane/ platinum-based therapy. Ann Oncol. 2012;23(10):2605-12.

29. Friedlander $\mathrm{M}$, Trimble $\mathrm{E}$, Tinker $\mathrm{A}$, et al. Clinical trials in recurrent ovarian cancer. Int J Gynecol Cancer. 2011;21(4):771-5.

30. Pignata S, Lorusso D, Scambia G, et al. Pazopanib plus weekly paclitaxel versus weekly paclitaxel alone for platinum-resistant or platinum-refractory 
advanced ovarian cancer (MITO 11): a randomised, open-label, phase 2 trial. Lancet Oncol. 2015;16(5):561-8.

31. Pignata S, Scambia G, Bologna A, et al. Randomized controlled trial testing the efficacy of platinum-free interval prolongation in advanced ovarian Cancer: the MITO-8, MaNGO, BGOG-Ov1, AGO-Ovar2.16, ENGOT-Ov1, GCIG study. J Clin Oncol. 2017;35(29):3347-53.

32. Monk BJ, Herzog TJ, Kaye SB, et al. Trabectedin plus pegylated liposomal doxorubicin (PLD) versus PLD in recurrent ovarian cancer: overall survival analysis. Eur J Cancer. 2012;48(15):2361-8.

33. Teplinsky E, Herzog TJ. The efficacy of trabectedin in treating ovarian cancer. Expert Opin Pharmacother. 2017;18(3):313-23.

34. AVASTIN (bevacizumab) Prescribing Label F. AVASTIN (bevacizumab) Prescribing Label. 2004; https:/www.accessdata.fda.gov/drugsatfda_docs/ label/2009/125085s0169lbl.pdf.

35. Aghajanian C, Blank SV, Goff BA, et al. OCEANS: a randomized, double-blind, placebo-controlled phase III trial of chemotherapy with or without bevacizumab in patients with platinum-sensitive recurrent epithelial ovarian, primary peritoneal, or fallopian tube cancer. J Clin Oncol. 2012;30(17):2039-45.

36. Aghajanian C, Goff B, Nycum LR, Wang YV, Husain A, Blank SV. Final overall survival and safety analysis of OCEANS, a phase 3 trial of chemotherapy with or without bevacizumab in patients with platinum-sensitive recurrent ovarian cancer. Gynecol Oncol. 2015;139(1):10-6.

37. Coleman RL, Brady MF, Herzog TJ, et al. Bevacizumab and paclitaxelcarboplatin chemotherapy and secondary cytoreduction in recurrent, platinum-sensitive ovarian cancer (NRG oncology/gynecologic oncology group study GOG-0213): a multicentre, open-label, randomised, phase 3 trial. Lancet Oncol. 2017;18(6):779-91.

38. Wu YS, Shui L, Shen D, Chen X. Bevacizumab combined with chemotherapy for ovarian cancer: an updated systematic review and meta-analysis of randomized controlled trials. Oncotarget. 2017;8(6):10703-13.

39. Oza AM, Selle F, Davidenko I, et al. Efficacy and safety of Bevacizumabcontaining therapy in newly diagnosed ovarian Cancer: ROSiA single-arm Phase 3B study. Int J Gynecol Cancer. 2017;27(1):50-8.

40. Chan SL, Mok T. PARP inhibition in BRCA-mutated breast and ovarian cancers. Lancet. 2010;376(9737):211-3.

41. Qian X, Qin J, Pan S, Li X, Pan Y, Ma S. Maintenance therapy in ovarian Cancer with targeted agents improves PFS and OS: a systematic review and meta-analysis. PLoS One. 2015;10(9):e0139026.

42. Hope JM, Blank SV. Current status of maintenance therapy for advanced ovarian cancer. Int J Women's Health. 2010;1:173-80.

43. Rossi L, Verrico M, Zaccarelli E, et al. Bevacizumab in ovarian cancer: a critical review of phase III studies. Oncotarget. 2017;8(7):12389-405.

44. Oza AM, Cook AD, Pfisterer J, et al. Standard chemotherapy with or without bevacizumab for women with newly diagnosed ovarian cancer (ICON7): overall survival results of a phase 3 randomised trial. Lancet Oncol. 2015; 16(8):928-36.

45. Liu JF, Matulonis UA. Bevacizumab in newly diagnosed ovarian cancer Lancet Oncol. 2015;16(8):876-8.

46. du Bois A, Floquet A, Kim JW, et al. Incorporation of pazopanib in maintenance therapy of ovarian cancer. J Clin Oncol. 2014;32(30):3374-82.

47. du Bois A, Kristensen G, Ray-Coquard I, et al. Standard first-line chemotherapy with or without nintedanib for advanced ovarian cancer (AGO-OVAR 12): a randomised, double-blind, placebo-controlled phase 3 trial. Lancet Oncol. 2016;17(1):78-89.

48. Elit L, Hirte H. Palliative systemic therapy for women with recurrent epithelial ovarian cancer: current options. Onco Targets Ther. 2013;6:107-18.

49. Uyar D. Promise seen with frontline Pembrolizumab plus chemotherapy in ovarian Cancer. March 28, 2018; http://www.targetedonc.com/news/promiseseen-with-frontline-pembrolizumab-plus-chemotherapy-in-ovarian-cancer.

50. Sisay M, Edessa D. PARP inhibitors as potential therapeutic agents for various cancers: focus on niraparib and its first global approval for maintenance therapy of gynecologic cancers. Gynecol Oncol Res Pract. 2017;4:18.

51. Pujade-Lauraine E, Ledermann JA, Selle F, et al. Olaparib tablets as maintenance therapy in patients with platinum-sensitive, relapsed ovarian cancer and a BRCA1/2 mutation (SOLO2/ENGOT-Ov21): a double-blind, randomised, placebocontrolled, phase 3 trial. Lancet Oncol. 2017;18(9):1274-84.

52. Mirza MR, Monk BJ, Herrstedt J, et al. Niraparib maintenance therapy in platinumsensitive, recurrent ovarian Cancer. N Engl J Med. 2016;375(22):2154-64.

53. Swisher EM, Lin KK, Oza AM, et al. Rucaparib in relapsed, platinum-sensitive high-grade ovarian carcinoma (ARIEL2 part 1): an international, multicentre, open-label, phase 2 trial. Lancet Oncol. 2017;18(1):75-87.
54. Coleman RL, Oza AM, Lorusso D, et al. Rucaparib maintenance treatment for recurrent ovarian carcinoma after response to platinum therapy (ARIEL3): a randomised, double-blind, placebo-controlled, phase 3 trial. Lancet. 2017; 390(10106):1949-61.

55. Coleman RL, Sill MW, Bell-McGuinn K, et al. A phase II evaluation of the potent, highly selective PARP inhibitor veliparib in the treatment of persistent or recurrent epithelial ovarian, fallopian tube, or primary peritoneal cancer in patients who carry a germline BRCA1 or BRCA2 mutation - an NRG oncology/gynecologic oncology group study. Gynecol Oncol. 2015;137(3):386-91.

56. Domchek SM, Aghajanian C, Shapira-Frommer R, et al. Efficacy and safety of olaparib monotherapy in germline BRCA1/2 mutation carriers with advanced ovarian cancer and three or more lines of prior therapy. Gynecol Oncol. 2016;140(2):199-203.

57. Karen Anne Cadoo CA, Fraser C, Milner A, Kolvenbag G. A phase 2 study to assess olaparib by homologous recombination deficiency status in patients with platinum-sensitive, relapsed, ovarian, fallopian tube, or primary peritoneal cancer. Journal of Clinical Oncology. 2017;35:15.

58. Kummar S, Oza AM, Fleming GF, et al. Randomized trial of Oral cyclophosphamide and Veliparib in high-grade serous ovarian, primary peritoneal, or fallopian tube cancers, or BRCA-mutant ovarian Cancer. Clin Cancer Res. 2015;21(7):1574-82.

59. Dockery LE, Gunderson CC, Moore KN. Rucaparib: the past, present, and future of a newly approved PARP inhibitor for ovarian cancer. Onco Targets Ther. 2017;10:3029-37.

60. Katherine M. Bell-McGuinn WEB, Russell J. Schilder, Paula M Fracasso, Kathleen N. Moore, Joan L. Walker, Linda R. Duska, Cara Amanda Mathews, Alice Chen, Stacie Peacock Shepherd, Vincent L. Giranda, Carol Aghajanian,. A phase I study of continuous veliparib in combination with IV carboplatin/paclitaxel or IV/IP paclitaxel/cisplatin and bevacizumab in newly diagnosed patients with previously untreated epithelial ovarian, fallopian tube, or primary peritoneal cancer: An NRG Oncology/Gynecologic Oncology Group study. Journal of Clinical Oncology. 2015;33(15_suppl).

61. Matulonis UA, Monk BJ. PARP inhibitor and chemotherapy combination trials for the treatment of advanced malignancies: does a development pathway forward exist? Annals of Oncology. 2017;28:3.

62. Matulonis UA WG, Barry W, Birrer M, Westin S, Spagnoletti T, Bell-McGuinn K, Obermayer E, Whalen C, Aghajanian C, Solit D, Mills G, Cantley L, Winer E, Phase I of oral BKM120 or BYL719 and olaparib for high-grade serous ovarian cancer or triple-negative breast cancer: final results of the BKM120 plus olaparib cohort. Cancer Research. 2015;75(15 supplement).

63. Michalarea VLD, Lopez J, Carreira S, Hassam H, Parmar M, Sathiyayogan N, Turner A, Hall E, Fandos SS, Seeramreddi S, Decordova S, Swales K, Ruddle R, Raynaud F, Tunariu N, Attard G, Molife LR, Banerji U, Plummer R, de Bono JS, Yap TA. Accelerated phase I trial of two schedules of the combination of the PARP inhibitor olaparib and AKT inhibitor AZD5363 using a novel intrapatient dose escalation design in advanced cancer patients. Cancer Res. 2015.

64. Liu JF, Barry WT, Birrer M, et al. Combination cediranib and olaparib versus olaparib alone for women with recurrent platinum-sensitive ovarian cancer: a randomised phase 2 study. Lancet Oncol. 2014;15(11):1207-14.

65. Moore K, Colombo N, Scambia G, et al. Maintenance Olaparib in patients with newly diagnosed advanced ovarian cancer. N Engl J Med. 2018;379:2495-505.

66. Ray-Coquard I, Selle F, Harter P, et al. PAOLA-1: An ENGOT/GCIG phase III trial of olaparib versus placebo combined with bevacizumab as maintenance treatment in patients with advanced ovarian cancer following first-line platinum-based chemotherapy plus bevacizumab. Journal of Clinical Oncology. 2016;34(15_suppl):TPS5607-TPS5607.

67. W. Graybill Y. Li I.A. Malinowska M.R. Mirza I. Vergote B. Pothuri B.J. Monk, AGMLARPSBJBDMOMAMOAFHCVDMP. 986TiP: A randomized, double-blind, placebo-controlled multicenter phase 3 trial of niraparib maintenance treatment in patients with advanced ovarian cancer following frontline chemotherapy. Annals of Oncology. 2017;28(suppl_5).

68. Ledermann $\mathrm{JA}$, Harter $\mathrm{P}$, Gourley $\mathrm{C}$, et al. Overall survival in patients with platinum-sensitive recurrent serous ovarian cancer receiving olaparib maintenance monotherapy: an updated analysis from a randomised, placebocontrolled, double-blind, phase 2 trial. Lancet Oncol. 2016;17(11):1579-89.

69. Swisher EM, McNeish IA, Coleman RL, et al. ARIEL 2/3: An integrated clinical trial program to assess activity of rucaparib in ovarian cancer and to identify tumor molecular characteristics predictive of response. 2014;32(15_suppl): TPS5619-TPS5619. 
70. Fong PC, Yap TA, Boss DS, et al. Poly (ADP)-ribose polymerase inhibition: frequent durable responses in BRCA carrier ovarian cancer correlating with platinum-free interval. J Clin Oncol. 2010;28(15):2512-9.

71. Michael Friedlander VG, Gibbs E, Bloomfield R, Hilpert F, Wenzel LB. Healthrelated quality of life (HRQOL) and patient-centered outcomes with maintenance olaparib compared with placebo following chemotherapy in patients with germline (g) BRCA-mutated $(\mathrm{m})$ platinum-sensitive relapsed serous ovarian cancer (PSR SOC): SOLO2 phase III trial. J Clin Oncol. 2017;35(15):-5507.

72. LYNPARZA॰ (olaparib) Receives Positive EU CHMP Opinion in PlatinumSensitive Relapsed Ovarian Cancer. AstraZeneca and Merck's New LYNPARZA Tablet Formulation Recommended for Maintenance Therapy Regardless of BRCA Status [press release]. 2018.

73. Rucaparib Boosts Progression-free Survival in BRCA Mutant Recurrent Ovarian Cancer. https:/www.esmo.org/Conferences/Past-Conferences/ESMO-2017Congress/Press-Media/Press-Releases/Rucaparib-Boosts-Progression-FreeSurvival-BRCA-Mutant-Recurrent-Ovarian-Cancer [press release]. 2017.

74. AA-S JRF, Liang MI, Ehrisman JA, Cohn DE, Jewell E, Havrilesky LJ. Bevacizumab, TKI, or PARPi? A targeted approach using composite valuebased endpoints and biomarkers to individualize care for platinum-sensitive recurrent ovarian cancer (PSROC). Gynecol Oncol. 2018;149(1):10-1.

75. Juliet Elizabeth Wolford JB, Lindsey E. Minion, Robin Keller, Ramez Nassef Eskander, John K. Chan, Bradley J. Monk, Krishnansu Sujata Tewari, . Abstract No: 5508, Cost-effectiveness of maintenance therapy in advanced ovarian cancer: Paclitaxel, bevacizumab, niraparib, rucaparib, olaparib, and pembrolizumab. 2018 ASCO Annual Meeting 2018; http://abstracts.asco. org/214/AbstView_214_220873.html.

\section{Publisher's Note}

Springer Nature remains neutral with regard to jurisdictional claims in published maps and institutional affiliations.

Ready to submit your research? Choose BMC and benefit from:

- fast, convenient online submission

- thorough peer review by experienced researchers in your field

- rapid publication on acceptance

- support for research data, including large and complex data types

- gold Open Access which fosters wider collaboration and increased citations

- maximum visibility for your research: over $100 \mathrm{M}$ website views per year

At $\mathrm{BMC}$, research is always in progress.

Learn more biomedcentral.com/submissions 